\title{
Adapting the ethical review process for COVID-19 research: reviewers' perspectives from Pakistan
}

\author{
Sualeha Shekhani, ${ }^{1}$ Saima Iqbal ${ }^{2}$ and Aamir Jafarey ${ }^{1}$
}

${ }^{1}$ Centre of Biomedical Ethics and Culture, Sindh Institute of Urology and Transplantation (SIUT), Karachi, Pakistan (Correspondence to: A.M. Jafarey: aamirjafarey@gmail.com). ${ }^{2}$ Department of Family Medicine, Shifa College of Medicine, Shifa Tameer-e-Millat University, Islamabad, Pakistan.

\begin{abstract}
Background: Research ethics committees (RECs) globally have adapted their responses to provide timely reviews of research proposals in the wake of the COVID-19 pandemic. The REC of the National Bioethics Committee (NBC) of Pakistan has followed suit.

Aims: To explore perceptions of NBC-REC reviewers who reviewed COVID-19 research proposals while describing the newly instituted Rapid Turnaround Review (RTR) system.

Methods: This cross-sectional study used 3 methods of data collection: a demographic questionnaire filled in by permanent members and co-opted reviewers; qualitative in-depth interviews conducted with both groups; and document review related to COVID-19 research proposals.

Results: Eight permanent members and 3 co-opted members participated. Under the RTR system, the time for review was established as 72 hours after receipt of the proposal. The Committee reviewed 55 projects over 10 months. Participants described numerous strengths of the new system, including introduction of online discussions via Zoom as well as presence of co-opted members leading to learning opportunities, particularly for junior members. The RTR system also allowed NBC-REC to gain recognition it had not enjoyed previously. Challenges identified by respondents included initial difficulty in initiating the system and tighter deadlines that may have compromised review quality. Poor scientific quality of proposals, compounded by external pressures to provide rapid approval, added to reviewers' frustrations. While fruitful, the RTR system was considered unsustainable beyond a public health emergency.
\end{abstract}

Conclusion: Adaptation of ethical review processes is essential in emergencies, however, existing guidelines have to be modified to suit contextual needs.

Citation: Shekhani S; Iqbal S; Jafarey A. Adapting the ethical review process for COVID-19 research: reviewers' perspectives from Pakistan. East Mediterr Health J. 2021;27(11):1045-1051. https://doi.org/10.26719/emhj.21.053

Received: 05/01/21; accepted: 13/04/21

Copyright @ W World Health Organization (WHO) 2021. Open Access. Some rights reserved. This work is available under the CC BY-NC-SA 3.o IGO license (https://creativecommons.org/licenses/by-nc-sa/3.o/igo)

\section{Introduction}

Ethical review is a core aspect of human research. In the wake of the COVID-19 pandemic, there has been an exponential increase globally in the number of research projects investigating its various aspects. For instance, 4094 clinical trials in various phases were listed for COVID-19 on clinicaltrials.gov as of December 2020 (1). While it is an ethical imperative to conduct research during public health emergencies, cutting corners in scientific or ethical aspects is never acceptable. Instead, research ethics committees (RECs), tasked with the responsibility of ethical review, have to adapt their processes to facilitate research in such times, while reducing obstacles (2). Ethical preparedness is therefore essential during humanitarian emergencies to ensure unhindered research (3).

According to a 2009 mapping exercise conducted in the World Health Organization Eastern Mediterranean Region, Pakistan was among the 15 countries that reported having a national REC (4). The Pakistani REC is a subcommittee of the National Bioethics Committee (NBC). Since 2004, the NBC-REC has been reviewing all human research that has foreign or Pakistani
Government funding, or research proposed to be conducted in multiple provinces of Pakistan. Additionally, all clinical trials, irrespective of location, or funding come to the NBC-REC. Prior to the COVID-19 pandemic, all NBC-REC reviews were conducted asynchronously, with proposal packages being sent electronically to members with a 6-week turnaround time. The Committee had no mechanism for rapid review prior to the pandemic and all proposals were reviewed according to the regular schedule. However, the anticipated increase in research reviews in the wake of the COVID-19 pandemic led to the introduction of a national rapid turnaround review (RTR) system, catering specifically to the public health emergency situation. While devising this system within the Pakistani context, it was important to ensure that it was not open to misuse for rapid reviews for routine research merely because the researchers were in a hurry, or could use their influence to pass through the system quickly. Cognizant of the challenges, the NBC-REC modified its terms of reference (TORs) to adapt to an RTR system, with a 72-hour response time for research proposals studying situations related to public health emergencies, such as COVID-19. To ensure immediate 
deliberation by the Committee, videoconferencing for each review was also instituted. This meant that such virtual meetings were happening up to 3 times a week at the peak of the first wave of the COVID-19 pandemic. The NBC-REC also made a provision in the TORs to co-opt relevant reviewers, as needed. The TORs were adapted from a guidance document by WHO (5).

The present study investigated the procedural aspects of the RTR system through a document review, and explored the perspectives of the reviewers with respect to the strengths and challenges encountered with the system. Some descriptive reports have recently summarized the experience of RECs during the COVID-19 pandemic $(6,7)$; however, to the best of our knowledge, this is the first study to utilize qualitative methods to explore the perspectives of national REC members. This study will contribute a useful low and middle income country perspective in an area with, as yet, little empirical analysis.

\section{Methods}

This cross-sectional study used 3 methods of data collection, including: a document review of projects reviewed under the RTR system; a demographic questionnaire to collect basic information about NBC-REC members; and a semistructured interview guideline, prepared specifically for the purpose of this study, to explore perceptions of members regarding the RTR system.

After obtaining informed consent from all participants, which included both permanent and coopted members, demographic information was collected by email and in-depth interviews were conducted online via the Zoom platform. Ethical clearance was obtained from the Institutional Review Board of Shifa Tameer-eMillat University, Islamabad.

Interviews, conducted in a mixture of English and Urdu, lasted 25 minutes to 1 hour. Interviews were audiorecorded to aid recordkeeping and later transcribed verbatim. Two authors of this paper, serving on the NBCREC, provided narratives regarding their experiences that contributed towards triangulation of data.

All transcriptions (and the 2 narrative experiences) were deidentified and assigned unique identification codes. Data from all sources were collated for analysis. For the qualitative part, themes and subthemes were developed inductively from the collated data using a modified version of the grounded theory known as constant comparison method (8). This method involved a series of steps that included: 1) reading transcripts multiple items by all 3 authors individually, and assigning codes in the process, known as open coding; 2) comparing codes from collated data, and identifying common patterns using axial coding; and 3) the eventual emergence of themes and subthemes. All 3 authors agreed upon the thematic framework presented in the Results.

\section{Results}

There were 11 participants included in the demographic and qualitative arms of this study, which included 8 permanent NBC-REC members and 3 co-opted reviewers. In-depth interviews were conducted with 9 participants and 2 members shared their experiences in a written narrative form. Data from demographic questionnaire, document review and the thematic framework from the qualitative arm (Table 1) are presented below.

\section{Demographic characteristics of participants}

Participants' demographic characteristics are summarized in Table 2.

\section{Characteristics of proposals reviewed under RTR system}

A review of NBC-REC records revealed that from April to the first week of December 2020, when these data were compiled, the Committee reviewed 55 COVID-19-related research proposals. Forty-seven proposals were given approval to proceed; 3 on first review, 42 after more than 1review, and 2 were granted exemption. Each review occurred within the mandated 72 hours. However, on average, the back and forth between the Committee and the applicant took 3-4 weeks before approval. Out of the 5 cases for which approval was not granted, the prime reason was inadequate response to concerns raised by the reviewers. One of these projects was the only instance in which the NBC-REC took $>72$ hours to review, since external scientific input was required. Concerns of the reviewers and the scientific experts were conveyed to the research team, in writing and during a special videoconference with the applicants. However, the Committee had not heard back from the researchers at the time of this study. One proposal was withdrawn by the researcher and 2 proposals were rejected.

Overall, 135 proposals were reviewed by the Committee when 77 non-COVID-19 proposals were included. Ten of these were pending final approval at the time of finalizing this dataset. Many of the non-COVID-

\begin{tabular}{|c|c|c|}
\hline Sr. no. & Themes & Subthemes \\
\hline \multirow[t]{4}{*}{1} & \multirow{4}{*}{$\begin{array}{l}\text { Strengths of the } \\
\text { RTR system }\end{array}$} & Addition of video meetings \\
\hline & & Logistic advantages of RTR system \\
\hline & & Presence of co-opted members \\
\hline & & Increased recognition of NBC-REC \\
\hline \multirow[t]{5}{*}{2} & \multirow{5}{*}{$\begin{array}{l}\text { Challenges of the } \\
\text { RTR system }\end{array}$} & Roadblocks in initiating the system \\
\hline & & Difficulties in time management \\
\hline & & Poor quality of proposals \\
\hline & & Lack of preparedness \\
\hline & & External pressures \\
\hline 3 & $\begin{array}{l}\text { Sustainability of } \\
\text { the RTR system }\end{array}$ & $\mathrm{N} / \mathrm{A}$ \\
\hline
\end{tabular}




\begin{tabular}{ll}
\hline $\begin{array}{l}\text { Table } 2 \text { Demographic characteristics of participants } \\
\text { Characteristics }\end{array}$ & No. of participants \\
Type of reviewer & 8 \\
Regular & 3 \\
Co-opted & \\
Sex & 5 \\
Male & 6 \\
Female & \\
Prior training/education in bioethics & 10 \\
Yes & 1 \\
No & \\
Professional background & 6 \\
Medical & 2 \\
Public health & 2 \\
Basic scientist & 1 \\
Clinical research administrator & 1 \\
No. of years in NBC-REC (only for regular \\
members) \\
4
\end{tabular}

19-related reviews were delayed beyond the routine mandated 6-week turnaround, and taken up once the pandemic peak subsided and regular research resumed. As a comparison, in 2019, 87 projects were received, of which 84 were approved.

\section{Strengths of the RTR system}

\section{Addition of videoconferences}

An identified strength of the RTR system was frequent videoconferencing, which provided reviewers with clarity in formulating their thoughts. These meetings became an avenue for learning by action, particularly for experienced members. Participants believed that their knowledge regarding the ethical and scientific aspects of the proposal increased: "Now I am more aware of the science, also Phase 1, Phase 2 trial.... [ I have learned] about how vaccine trials are done." (Participant 2)

\section{Logistic advantages of the RTR system}

Another important advantage of the RTR system was tighter deadlines that were helpful for some reviewers who worked better in this manner. In the initial weeks of the COVID-19 pandemic when lockdown was instituted, reviewers had more time to review projects rapidly, "Many evening activities were cancelled [because of lockdown]. So while it was pressuring [to conduct the review], we managed to still do it." (Participant 1) Another participant reported a similar experience, "We were not performing our professional duties. I was not going to my clinic at that time. So it was easy." (Participant 3)

\section{Presence of co-opted reviewers}

While the provision for co-opting reviewers had always existed, it was utilized more extensively during RTR. This occurred for 2 reasons: (1) paucity of scientific expertise within the permanent committee in certain areas being reviewed; and (2) to tap into expertise of people with experience in public health emergencies and research reviews. A committee member stated, "It was a very useful experience. We also learned from them. And at the same time, we were able to adequately address the situation." (Participant 3)

\section{Increased recognition of $\mathrm{NBC}-\mathrm{REC}$}

One unexpected outcome of the RTR system was increased recognition of the NBC-REC's role as a research governance body. Participants believed that researchers generally perceived regulatory and governance structures with disdain as roadblocks to research, since they often take a lot of time. However, due to rapid turnaround and extensive help in strengthening the proposals during the several review rounds, participants felt that the NBC-REC was facilitating rather than hindering research. According to a respondent who also served in the Secretariat of the Committee, this was a marked shift from the past. This occurred because, "The first response within 48 hours was extremely encouraging for them." (Participant 6) This new-found appreciation of the new system was reflected in a statement by Participant 6, "[The NBC secretariat] got emails from every single person, from every single PI, saying that they appreciate our work". In her opinion, this system allowed the NBC-REC as well as the individual members to get "fame with respect". Other participants also spoke along similar lines. "I think we made ourselves recognized at this time. We made our value known. Initially I used to think that no one listens to us [the REC]. But now I feel that during COVID, everyone, the media, the high authorities recognized our importance". (Participant 5)

\section{Challenges of the RTR system}

\section{Roadblocks in initiating the system}

While the need for such a system was felt early on in the COVID-19 pandemic, and was met with enthusiasm by committee members, prior approval by relevant government functionaries was essential before bringing any amendments to the working of the National Committee. Bringing about such interventions fell to the Secretariat. This required "going through multiple bureaucratic procedures" according to Participant 6 from the Secretariat. The pandemic had also created different priorities for the Government, and little attention was being paid to the work of the NBC, "Nobody knew about NBC, nobody knew about REC". (Participant 6) The problem was compounded because "All of our heads were changing, they were entirely new". (Participant 6) The designated NBC-REC member handled queries by government functionaries asking for justification for the proposed amend- 
ments in the TORs: "I answered that a lot of research is going to happen. I told them that this will be a situation [a large number of proposals] which will happen. I believe we must put in this system". (Participant 6)

\section{Difficulties in time management}

Once the system was in place, most members believed that strict timelines for reviewing the projects and responding to the investigators took a toll. This was heightened with the lifting of lockdown and people resuming their professional obligations. According to one, "When my official duties started, I could not fit in the review process". (Participant 5) For the Chair of the Committee, her professional obligations suffered due to extra time required for the RTR system. According to some respondents, because of multiple competing responsibilities, they were concerned about the quality of their review. One stated, "I did not review them as thoroughly as I would have liked to". (Participant 2) The number of proposals proved to be challenging as well, because according to Participant 5, "Before COVID-19, we did not have that many proposals that required review at so much speed".

\section{Poor quality of proposals}

Another challenge for all participants was the poor quality of proposals. This was attributed to overeager researchers wishing to join the fray, and hence submitting hastily put together proposals. Another challenge associated with poor quality was the bad science presented in the proposals: "Much of our time was spent fixing the science, rather than the ethics of it". (Participant 10) While this proved to be frustrating for many members, Participant 11 believed that it was their responsibility to do so in order to promote good research, "even if it meant the project going back and forth several times".

\section{Lack of preparedness}

Adding to the poor quality of proposals was the reviewers own discomfort and concern in reviewing technically challenging projects. For instance, studies involving molecular biology, stem cell approaches, vaccine trials, and testing of indigenously prepared ventilators led to significant discomfort among reviewers. This was circumvented by co-opting relevant members. Another problem while reviewing was a lack of preparedness or training for research reviews based on public health emergencies.

\section{External pressures}

Poor quality of proposals combined with political pressures to approve quickly, particularly for high-profile projects, also increased the burden of REC members, according to Participant 10. The Chair of the Committee and the Secretariat primarily absorbed these pressures. However, a senior member reported getting calls from the highest government quarters to proceed with quickly with the review process. Sometimes, external pressures on the Committee came via the NBC Secretariat, who would receive requests for rapid approvals (Participant 10). This happened when back and forth communication was going on between the Committee and the researchers asked to amend their proposals to conform to ethical and scientific requirements. However, members believed that the Secretariat should not have been used to put pressure on the Committee. As Participant 5 stated, "We should be free to work with our peace of mind".

\section{Sustainability of RTR system}

While the REC members took the RTR system in their stride, they believed that the process required a lot of commitment that would not be sustainable indefinitely (Participant 3). Increased risk of burnout for the reviewers was cited as one reason. In addition, in retrospect, the reviewers believed that the 72-hour commitment was ambitious (Participant 9). Given the gradual change in research proposals from clinical to sociological research, the deadline "could have been relaxed a bit". All respondents believed that while this system was excellent as a short-term emergency response, it could not exist under normal circumstances because "it really exhausts your energies" (Participant 6).

\section{Discussion}

The response of national health research organizations and ethical review committees after the onset of the COVID-19 pandemic was noteworthy in many parts of the world, with authorities developing and implementing processes to ensure timely review of research related to COVID-19 (9-11). The Pakistan NBC-REC developed its own response that, as this study demonstrated, was appreciated by reviewers and researchers. Furthermore, analysis of this RTR system has useful learning points for RECs within the developing world.

The new system necessitated online, real-time discussions through videoconferencing. This system was acknowledged as an advantage by all respondents. While videoconferencing is not a novel idea, this was never considered as an option by the NBC-REC prior to the COVID-19 pandemic (12). This system proved successful and provided guidance for the future since members of the REC are spread across the country, and allows realtime exchange of opinions and consensus building. The videoconferencing experience from the pandemic has provided guidance for the conduct of future committee meetings as well. If necessary, the Committee now meets online weekly to review COVID-19-related projects. Regular meetings are now scheduled fortnightly to clear the backlog of non-COVID-related projects delayed due to the pandemic.

Several guidelines have recommended that, to prepare for emergency public health research reviews, RECs should include relevant members (2). Since the TORs had this provision, a list of potential co-opted reviewers was developed and their inclusion in the review process started early. The presence of co-opted reviewers provided learning opportunities and enhanced review quality. However, it was easy to co-opt reviews since several senior members in the Committee personally knew people with relevant expertise who could provide high-quality input for the review process. It was useful 
to harness external expertise from overseas as well as national reviewers.

A welcome and unexpected outcome of the new rapid review system was that this Committee acquired a recognition and respect it previously did not enjoy. This is intriguing since ethical review processes are often considered impediments to research (12-14). This recognition of the positive role of the NBC was a direct result of its rapid response to researchers, in addition to extensive feedback to enhance the quality of proposals. Since it is mandatory for all clinical trials to be approved by the NBC-REC before commencing, a poorly functioning national review system would have derailed important research and earned a bad name for the Committee. As it transpired, the newly installed RTR system worked and was well received, with the NBC-REC earning a good name and being propelled into the national limelight; something that members considered their personal accomplishment. The new system also helped to build trust in the system of research ethics governance (12).

The RTR system naturally faced challenges and constraints. The regular workload on the Committee is reflected by its caseload in 2019, which was 87 proposals, with a 6-week response time. From April to December 2020, the Committee handled 55 COVID-19-related projects; all but 1 being responded to within 72 hours. Respondents therefore found their review responsibilities overwhelming due to the short turnaround time and frequent virtual meetings, at times happening thrice weekly. This increase in workload and changes in modus operandi of committees has emerged from other countries including Italy (15), the Philippines (16), China (16) and Islamic Republic of Iran (18). For example, in China, a committee that met only once a month prior to the pandemic met 4 times within 34 days (18).

In retrospect however, the 72-hour deadline could have been applied selectively to pertinent COVID-19 proposals, and in particular, social sciences projects could have been given longer turnaround periods. After the first peak of the COVID-19 pandemic, the REC saw a decrease in the number of proposals received, which led to increasing the turnaround time to 1 week for COVID19-related proposals.

Another serious challenge that study respondents recounted was the poor quality of proposals received. This was not considered surprising as disaster-related protocols are often developed in a hurry, without proper planning $(15,16)$. While improving science and methodology is not considered the domain of RECs, there was a strong feeling among committee members that bad science leads to bad ethics (17). The time involved in the back and forth communication between the Committee and researchers reflected the commitment by the members to their voluntary task. To bring about improvement in proposals, it is important to develop an adequate research culture within developing countries.
This study also highlights the importance of ethical review in going beyond just ethics and into the science of the proposal itself, to strengthen the structure of research ethics governance.

Apart from the challenge of poor-quality research proposals, another area of concern was external pressures from influential quarters, primarily to further expedite reviews stuck in a re-review process. The majority of proposals were reviewed and a decision conveyed to the researchers within the stipulated 72 hours, with only 1 exception. While it is important to facilitate the research process during a pandemic, no compromises on review quality should be made since the primary responsibility of RECs is to provide quality reviews. Such pressures were brought on by the Committee particularly for those proposals that were regarded as projects of national importance. However, members believed that these pressures were unfair since their job and responsibility was to ensure review quality rather than cater to the demands of powerful offices. However, such external pressures are not uncommon from this part of the world $(3,19)$.

An important finding of this study was that, while quick turnaround is essential for emergencies, it ought not be prolonged beyond a certain point, since it taxes the energies of the entire committee. The changes that COVID-19 has brought offers a unique window of opportunity for national and institutional RECs to develop innovative systems of oversight. We believe that the RTR system of the NBC-REC presents a workable model that other RECs can emulate.

This study had some limitations. Inclusion of 2 members from the NBC-REC in the research team may be perceived as a limitation because it may have induced bias, but the presence of a third researcher, unrelated to the REC, ensured that any bias was neutralized. The findings of this study reflect the experience of 1 national REC, and the small number of participants in the study may be regarded as a limitation. However, a qualitative analysis that included perspectives of all reviewers involved in the review process ensured richness of data.

We make the following recommendations in light of our study. The WHO guidance document for public health emergency research reviews is a good template, and can be contextualized for the needs of particular countries. Provisions must be made by national and institutional RECs to avail relevant outside expertise to maintain review quality and credibility. Face to face meetings enhance review quality, and videoconferencing is an excellent tool to enable such meetings when physical meetings are not possible. Additional training, even for seasoned members, particularly within the field of disaster ethics, should be provided. As epidemics and health disasters and emergencies continue to emerge, it is essential that RECs are equipped in ethics preparedness. 


\section{Acknowledgement}

The authors wish to acknowledge Mr. Hamza Jafarey who transcribed all the interviews.

Funding: Supported by a grant from WHO/EMRO Division of Science, Information and Dissemination: 2020/1068517-0.

Competing interests: None declared.

\section{Adaptation du processus d'examen éthique de la recherche sur la COVID-19 : points de vue des examinateurs au Pakistan}

\section{Résumé}

Contexte: Partout dans le monde, les comités d'éthique de la recherche (CER) ont adapté leurs réponses afin d'examiner en temps utile les propositions de recherche formulées dans le sillage de la pandémie de COVID-19. Le CER du Comité national de bioéthique (CNB) du Pakistan s'est lui aussi adapté.

Objectifs : Explorer les points de vue des examinateurs du CER-CNB qui ont étudié les propositions de recherche sur la COVID-19 et décrire en parallèle le nouveau système d'examen accéléré mis en place.

Méthodes: La présente étude transversale a utilisé trois méthodes de collecte de données: un questionnaire démographique rempli par les membres permanents et les examinateurs cooptés; des entretiens qualitatifs approfondis menés avec les deux groupes; et un examen documentaire relatif aux propositions de recherche sur la COVID-19.

Résultats: Huit membres permanents et trois membres cooptés ont participé à l'étude. Dans le cadre du système d'examen accéléré, le délai d'examen a été fixé à 72 heures après réception de la proposition. Le comité a examiné 55 projets sur 10 mois. Les participants ont décrit les nombreux points forts du nouveau système, notamment l'introduction de discussions en ligne via Zoom, ainsi que la présence de membres cooptés, ces deux nouveautés offrant des possibilités d'apprentissage, en particulier pour les examinateurs juniors. Le système d'examen accéléré a également permis au CER-CNB d'obtenir un degré de reconnaissance sans précédent. Les défis identifiés par les répondants comprenaient la difficulté initiale à mettre en place le système, et des délais plus serrés qui auraient pu compromettre la qualité de l'examen. La piètre qualité scientifique des propositions, aggravée par des pressions externes en faveur d'une approbation rapide, a accentué la frustration des examinateurs. Bien que concluant, le système d'examen accéléré a été jugé comme non viable en dehors d'une situation d'urgence de santé publique.

Conclusion: L'adaptation des processus d'examen éthique est indispensable en situation d'urgence. Cependant, les lignes directives existantes doivent être modifiées en fonction des besoins du contexte.

$$
\text { تكييف المراجعة الأخلاقية لبحوث كوفيد-19: وجهات الحيات نظر المراجعين من باكستان }
$$

الخلفية: واءمت لجان مر اجعة أخلاقيات البحوث حول العالم استجاباتها كي تُقدّم مر اجعات مناسبة التوقيت للمشاريع البحثية في أعقاب انتشار

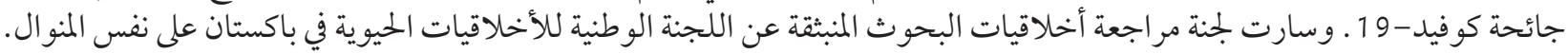

الأهداف: هدفت هذه الدراسة المى استكشاف تصورات مراجعي لجنة مراجعة أخلاقيات البحوث المنبثقة عن اللجنة الوطنية للأخلاقيات الحيوية الذين استعرضوا المشروعات البحثية المتعلقة بكوفيد-19 مع وصف الف نظام الاستعر اض سريع الدوران الذي الذي أنشئ حديثًا.

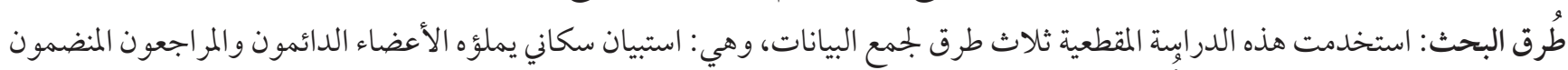

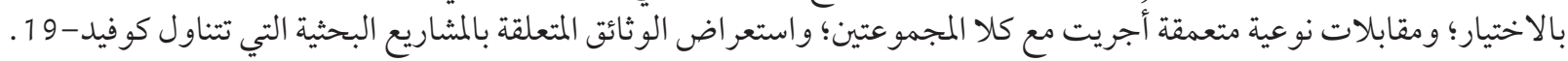

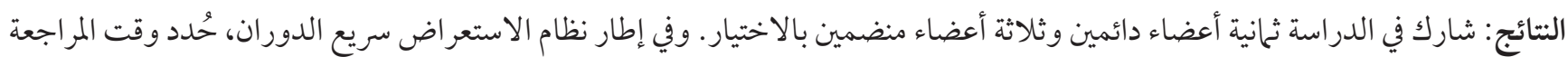

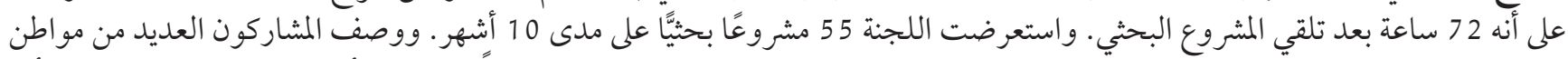

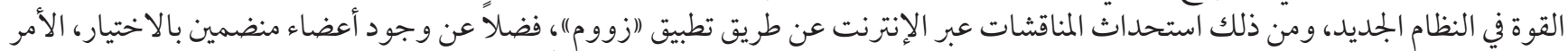

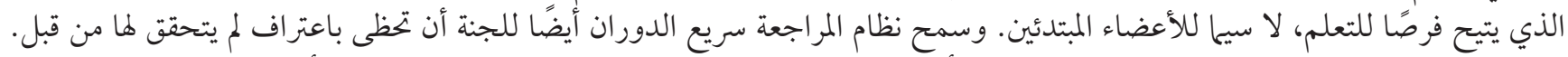

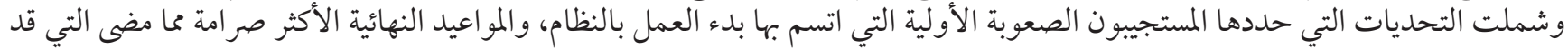

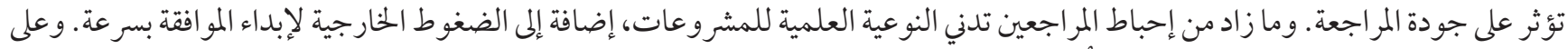

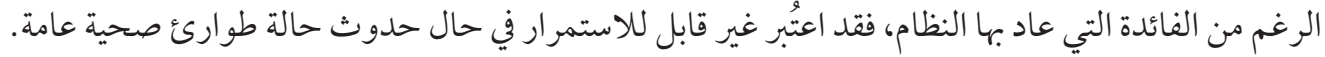

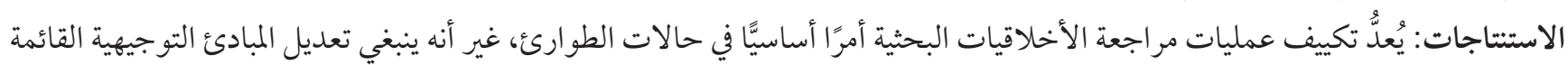
لتتناسب مع الاحتياجات التي يتطلبها نيفات السياق. 


\section{References}

1. Covid-19 information [website]. ClinicalTrials.gov.; 2021 (https://clinicaltrials.gov/ct2/results?cond=Covid-19\&term=\&cnt try $=\&$ state $=\&$ city $=\&$ dist, accessed 13 July 2021.

2. Guidance and strategies to streamline ethics review and oversight of COVID-19-related research. Washington DC: Pan American Health Organization; 2020 (https://www.paho.org/en/documents/guidance-and-strategies-streamline-ethics-review-and-oversight-covid-19-related-research, accessed 13 July 2021).

3. Kumar NK, Muthuswamy V. Fostering ethical biomedical and health research in India during the COVID-19 pandemic. Research Ethics. 2020 Jul;16(3-4). https://doi.org/10.1177/1747016120941632

4. Abou-Zeid A, Afzal M, Silverman HJ. Capacity mapping of national ethics committees in the Eastern Mediterranean Region. BMC Med Ethics. 2009 Jul 4;10:8. https://doi.org/10.1186/1472-6939-10-8 PMID:19575813

5. Guidance for research ethics committees for rapid review of research during public health emergencies. Geneva: World Health Organization; 2020 (https://www.who.int/publications/i/item/9789240006218, accessed 13 July 2021.

6. Agrawal V, Nath C, Mishra SK. Ethics committee meeting by video-conferencing during Covid-19. Indian J Med Ethics. 2020 May 27. https://doi.org/10.20529/IJME.2020.062 PMID:32546456

7. Sheehy A, James JR, Horgan M. Implementing a national approach to research ethics review during a pandemic - the Irish experience. HRB Open Research. 2020 Nov 16;3:63. https://doi.org/10.12688/hrbopenres.13146.2 PMID:33490861

8. Boeije H. A purposeful approach to the constant comparative method in the analysis of qualitative interviews. Qual Quant. 2002 Nov 1; 36(4):391-409. https://doi.org/10.1023/A:1020909529486

9. Position of the European Network of Research Ethics Committees (EUREC) on the Responsibility of Research Ethics Committees during the COVID-19 pandemic. EUREC; 2020 (https://ancei.es/wp-content/uploads/2020/05/EUREC-Positionpaper_COVID_19. pdf, accessed 13 July 2021).

10. Fast track review guidance for COVID-19 studies [website]. London: NHS Health Research Authority; 2020 (https://www.hra.nhs. uk/covid-19-research/fast-track-review-guidance-covid-19-studies/, accessed 13 July 2021).

11. ICMR, WHO India and ISCR jointly organized a webinar on ethics review for bio-medical projects during the pandemic [website]. World Health Organization South-East Asia Region; 2020 (https://www.who.int/india/news/detail/27-06-2020-icmr-who-ine dia-and-iscr-jointly-organized-a-webinar-on-ethics-review-for-bio-medical-projects-during-the-pandemic, accessed 13 July 2021 ).

12. Ghooi RB. Ethics committee meetings - online or face to face?. Perspect Clin Res. 2020 Jul-Sep;11(3):121-3. https://doi. org/10.4103/picr.picr_97_20 PMID:33033701

13. Brown C, Spiro J, Quinton S. The role of research ethics committees: friend or foe in educational research? An exploratory study. Br Educ Res J. 2020 Aug; 46(4):747-69. https://doi.org/10.1002/berj.3654

14. Jafarey AM, Iqbal SP, Hassan M. Ethical review in Pakistan: the credibility gap. J Pak Med Assoc. 2012 Dec;62(12):1354-7. PMID:23866494

15. Alirol E, Kuesel AC, Guraiib MM, de la Fuente-Núñez V, Saxena A, Gomes MF. Ethics review of studies during public health emergencies - the experience of the WHO ethics review committee during the Ebola virus disease epidemic. BMC Med Ethics. 2017 Dec 1;18(1):43. https://doi.org/10.1186/s12910-017-0201-1 PMID:28651650

16. Zhang H, Shao F, Gu J, Li L, Wang Y. Ethics committee reviews of applications for research studies at 1 hospital in China during the 2019 novel coronavirus epidemic. JAMA. 2020 May 12;323(18):1844-6. https://doi.org/10.1001/jama.2020.4362 PMID:32202608

17. Gelling L. Role of the research ethics committee. Nurse Educ Today. 1999 Oct 1;19(7):564-9. https://doi.org/10.1054/nedt.1999.0349

18. Hashemi A, Bahmani F, Saeedi Tehrani S, Forouzandeh M, Koohpayehzadeh J, Ashrafi M, et al. Ethical considerations and interdisciplinary approach to research on COVID-19 pandemic: the response of Iran University of Medical Sciences. Med J Islam Repub Iran. 2020 Jul 29;34:87. https://doi.org/10.34171/mjiri.34.87 PMID:33306052

19. Bompart F. Ethical rationale for better coordination of clinical research on COVID-19. Res Ethics. 2020 Jul;16(3-4):1-10. https:// doi.org/10.1177/1747016120931998 